\title{
PARAMETRIC X-RAY RADIATION IN THE BACKWARD GEOMETRY
}

\author{
V.I. Alekseev ${ }^{1}$, A.N. Eliseyev $^{1}$, E.F. Irribarra ${ }^{3}$, I.A. Kishin ${ }^{1,2}$, A.S. Kubankin ${ }^{1,2}$, \\ R.M. Nazhmudinov ${ }^{1,2}$ \\ ${ }^{I}$ P.N. Lebedev Physical Institute RAS, Moscow, Russia; \\ ${ }^{2}$ Belgorod National Research University, Belgorod, Russia; \\ ${ }^{3}$ Escuela Politécnica Nacional, Departamento de Física, Quito, Ecuador
}

Parametric X-ray Radiation registered in the backward geometry is analysed. The main properties of the radiation for such geometry are discussed. The advantages of the backward geometry over other configurations regarding the intensity, the spectral width and the possibility to discriminate the contributions form different radiation mechanisms to the total radiation yield are presented.

PACS: $537.8,538.9,535-1 /-3,535.4,537.5$

The radiation produced during the interaction of charged particles with matter possesses several characteristics which depend on the nature of the generation mechanism.

Characteristic X-ray radiation for example is isotropic. The registered spectrum does not dependent on the observation geometry. On the other hand, the radiation produced during the interaction of charged particles with periodic structures presents a strong dependence of the spectral characteristics on the observation angle [1 - 4].

The radiation can be detected in every direction defined by the solid angle $4 \pi$. It has been shown theoretically and experimentally that parameters such the peaks intensity and spectral width change substantially when the observation angle $\theta$ changes.

It turns out that Parametric X-ray Radiation PXR acquires interesting properties when the radiation is detected in the opposite direction to the incident charged particles velocity. The geometry can be achieved if charged particles move across a magnetic field as presented in Fig. 1. For this scheme, the observation angle equals $\pi$. This configuration to register the radiation has been referred as "The backward geometry", "The backscattering geometry" or "Extreme Bragg case". The properties of PXR for such geometry have been explored theoretically and experimentally [4 - 7].

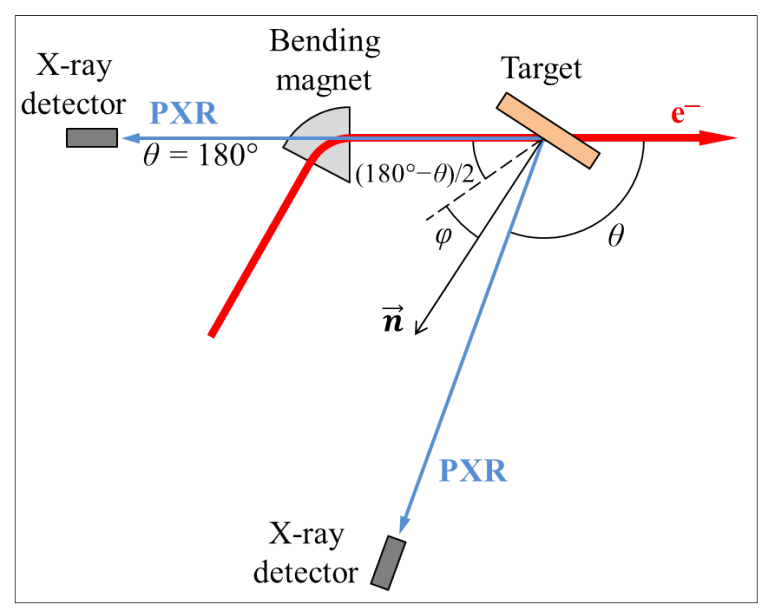

Fig. 1. General experimental setup: $\theta$-observation angle, $\varphi$-orientation angle, $\vec{n}$-normal vector to the target surface

The backward geometry presents some advantages over other geometries because of three important reasons.
The study of PXR from polycrystals is of great interest because among other reasons, there is a possibility to determine the atomic structure of such materials based on the spectral-angular characteristics of the obtained radiation. An obstacle to apply this mechanism of radiation in the diagnostics of materials was the small intensity of the PXR peaks which can be overlapped in the spectrum by the radiation background.

This was solved in [4] where it was predicted that in the backward geometry the intensity of the PXR peak is proportional and the spectral width inversely proportional to square of the Lorentz factor $\gamma$ of the incident charged particle. Under different observation angles this dependence has the first power. Both effects can be listed as the first two advantages of the backward geometry and have been dynamically verified in an experiment with textured polycrystals [8].

In Fig. 2 is presented the behaviour of the spectral width of the PXR peakfrom the crystallographic plane (200) when the observation angle changes. Data was obtained during the interaction of a $7 \mathrm{MeV}$ electron beam with a tungsten textured polycrystalline foil. It is easy to observe that the spectral width decreases when $\theta$ approaches $\pi$.

To highlight the effect, the energy resolution of the detector AMPTEK was studied between 1.5 and $9 \mathrm{keV}$. Since the natural spectral width of the CXR peaks constitutes several electronvolts [9] and it is smaller than the detector energy resolution, the spectral width of the measured CXR peaks can be regarded as the detector energy resolution $\Delta E(\omega)$ for a determined energy $\omega$. In Fig. 2 the dots represent the FWHM of CXR peaks of different elements determined by a Gaussian fitting of the registered data.

This information allows to determine the detector energy resolution at $\omega=5.9 \mathrm{keV}$ which is used to construct the theoretical curve of the detector energy resolution (see shown in blue in Fig. 2) according to the detector characteristics [10]:

$$
\Delta E(\omega)=\sqrt{\left(\Delta E_{\omega=5.9 \mathrm{keV}}\right)^{2}-120^{2}+2240 \omega},
$$

where $\Delta E(\omega)$ - detector energy resolution measured in electronvolt, $\Delta E_{\omega=5.9 \mathrm{keV}}-$ detector energy resolution at the energy $\omega=5.9 \mathrm{keV}$ measured in electronvolt and $\omega$ - photon energy measured in kiloelectronvolt. It can be observed that the curve fits the FWHM of the CXR peaks. 
It should be remarked that the behaviour of the PXR spectral width is not determined by the change of the detector energy resolution. The change of the spectral width is inherent to the PXR radiation mechanism.

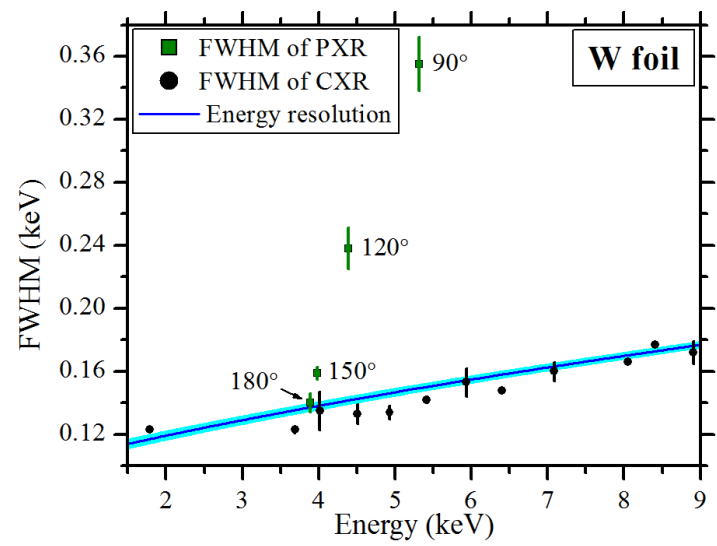

Fig. 2. Dependence of the PXR peak spectral width on the observation angle. The solid curve represents the detector energy resolution calculated based on FWHM of CXR peaks. The fitting error is represented by the thickness of the curve

It can be observed that the PXR peak spectral width in the backward geometry reaches the value of the detector energy resolution. This effect agrees with theory [4] since theoretical predictions estimate that it has an order of $10 \mathrm{keV}$ which is much smaller than $\Delta E(\omega)$. Additional studies to determine the intrinsic spectral width of PXR peaks is required. This can be probably achieved using a X-ray monochromator.

The next advantage of the backward geometry is related to the experimental discrimination of the contribution from different radiation mechanisms to the total yield. It should be mentioned that when charged particles interact with periodic structures the total radiation yield is composed by the sum (interference) of mechanisms such bremsstrahlung, characteristic, parametric, diffracted transition radiation which can be manifested simultaneously.

Theoretically, the yields of different radiation mechanisms are described independently but their experimental discrimination is a difficult task that cannot be always achieved, complicating in this way the comparisons of experimental data with theory, especially when the characteristics of the radiation produced by different mechanisms are similar. The difficulty to distinguish experimentally the contributions of PXR from the diffracted real photons produced during the interaction of the charged particles with the same target (diffracted bremsstrahlung, diffracted transition radiation, etc.) is related to the close positions between the peak energies for those processes $[11,12]$.

It was shown that the backward geometry provides the necessary conditions to discriminate absolutely the contributions form diffraction of virtual and real photons to the total radiation field [13]. It was shown that for this geometry the contribution from Parametric Xray Radiation is located in an energy region that is forbidden for real photons diffraction since are below the minimal energy for Bragg diffraction processes.
In Fig. 3 are presented two spectra obtained from the tungsten foil in the backward geometry for two orientation angles $\varphi=-2^{\circ}$ and $\varphi=-10^{\circ}$. The Bragg energy is also illustrated as a vertical line at $\omega=3.924 \mathrm{keV}$. It can be observed that the PXR peak energy for $\varphi=-10^{\circ}$ is smaller than the Bragg energy limit. Consequently, diffraction of real photons generated for example by bremsstrahlung cannot give any contribution to this peak.

This effect can be used to study experimentally the fundamental questions of radiation generation discriminating the contributions of different mechanisms.

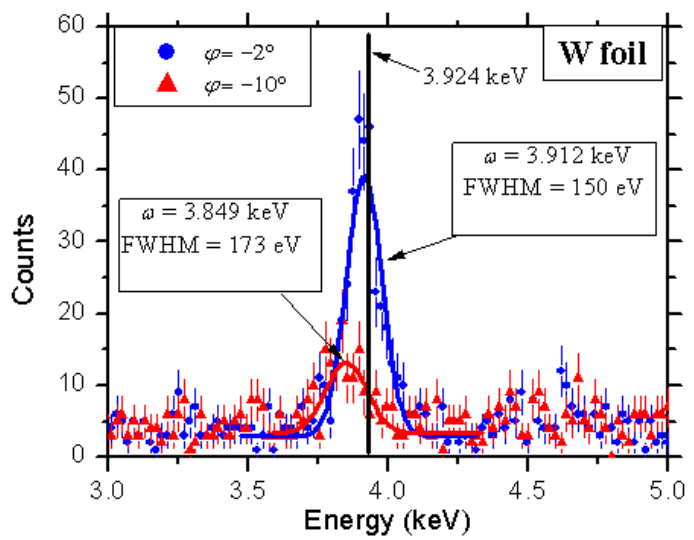

Fig. 3. PXR peak from the (200) crystallographic planefor different orientation angles of the tungsten foil. The vertical line represents the minimal energy for Bragg diffraction processes

It should be noted that the contributions from different radiation mechanisms can also be discriminated for other observation angles, however, any errors in the orientation of the crystal, solid angle, incident angle of the electron beam can lead to a shift of the expected photons energy to a region where other radiation mechanism could be manifested. Consequently, it can lead to an incorrect interpretation of the mechanism contributions. These kind of problems, cannot occur in the backward geometry.

Finally, the advantages of the backward geometry over other geometries concerning the PXR peak properties can be listed as follows:

- Amplitude is proportional to $\gamma^{2}$.

- Spectral width is proportional to $1 / \gamma^{2}$.

- Provides the conditions to discriminate the contributions form diffraction of virtual and real photons to the total radiation field.

\section{ACKNOWLEDGEMENTS}

The work was supported by a Program of the Ministry of Education and Science of the Russian Federation for higher education establishments, Project No. 3.1631.2017/PQ, by the grant of the President of Russia for young doctors of sciences MD-5748.2018.2 and by the project No. PIJ-16-03 of the Escuela Politécnica Nacional.

\section{REFERENCES}

1. Y. Fainberg, N.A. Khyzhniak. On parametric X-rays of fast charged particles in periodic media // Journal of Experimental and Theoretical Physics. 1957, v. 32, p. 883. 
2. V.G. Baryshevsky, I.D. Feranchuk, A.P. Ulyanenkov. Parametric $X$-ray Radiation in Crystals. 2005.

3. A.P. Potylitsyn. Electromagnetic Radiation of Electrons in Periodic Structures. Springer Berlin Heidelberg, 2011.

4. V. Astapenko, N. Nasonov, P. Zhukova. Anomalous peak in the spectrum of polarizational bremsstrahlung from relativistic electrons moving through a solid target // Journal of Physics B: Atomic, Molecular and Optical Physics. 2007, v. 40, p. 1337-1346.

5. M. Tabrizi. Influence of multiple scattering of relativistic electrons on the linewidth of Parametric Xray Radiation produced in the extremely Bragg geometry in the absence of photoabsorption // Radiation Physics and Chemistry. 2016, v. 127, p. 7-12.

6. J. Freudenberger, H. Genz, V.V. Morokhovskyi, A. Richter, J.P.F. Sellschop. Parametric X-Rays Observed under Bragg Condition: Boost of Intensity by a Factor of Two // Phys. Rev. Lett. 2000, v. 84, p. 270-273.

7. V.I. Alekseev, K.A. Vokhmyanina, A.N. Eliseev, P.N. Zhukova, A.S. Kubankin, R.M. Nazhmudinov, et al. Measuring coherent peaks of polarization bremsstrahlung from relativistic electrons in polycrystalline targets in backscattering geometry // Technical Physics Letters. 2012, v. 38, p. 294-296.

8. V.I. Alekseev, A.N. Eliseyev, E. Irribarra, I.A. Kishin, A.S. Klyuev, A.S. Kubankin, et al. Evolution of the characteristics of Parametric X-ray Radiation from textured polycrystals under different observation angles // Physics Letters A. 2018, v. 382, p. 503-506.

9. M.O. Krause, J.H. Oliver. Natural widths of atomic $\mathrm{K}$ and $\mathrm{L}$ levels, $\mathrm{K} \alpha \mathrm{X}$-ray lines and several KLL Auger lines // Journal of Physical and Chemical Reference Data. 1979, v. 8, p. 329-338.

10. AMPTEK, XR-100CR Si-PIN X-Ray Detector, 2014. Available at http://amptek.com/products/xr100 cr-si-pin-x-ray-detector/\#5, accessed on May 30 2019.

11. Y.N. Adischev, S.N. Arishev, A.V. Vnukov, A.V. Vukolov, A.P. Potylitsyn, S.I. Kuznetsov, et al. Angular distribution of X-ray radiation by $500 \mathrm{MeV}$ electrons in a tungsten crystal // Nuclear Instruments and Methods in Physics Research Section B: Beam Interactions with Materials and Atoms. 2003, v. 201, p. 114-122.

12. V.V. Morokhovskyi, J. Freudenberger, H. Genz, V.L. Morokhovskii, A. Richter, J.P.F. Sellschop. Theoretical description and experimental detection of the interference between parametric X-radiation and coherent bremsstrahlung // Phys. Rev. B. 2000, v. 61, p. 3347-3352.

13. V.I. Alexeyev, A.N. Eliseyev, E. Irribarra, I.A. Kishin, A.S. Kubankin, R.M. Nazhmudinov. Observation of parametric X-ray radiation in an anomalous diffraction region // Physics Letters A. 2016, v. 380, p. $2892-2896$.

Article received 10.06.2019

\section{ИССЛЕДОВАНИЕ ПАРАМЕТРИЧЕСКОГО РЕНТГЕНОВСКОГО ИЗЛУЧЕНИЯ В ГЕОМЕТРИИ «СТРОГО НАЗАД»}

\section{В.И. Алексеев, А.Н. Елисеев, Э.Ф. Иррибарра, И.А. Кищин, А.С. Кубанкин, Р.М. Нажсмуинов}

Анализируется параметрическое рентгеновское излучение, зарегистрированное в геометрии «строго назад». Обсуждаются основные свойства излучения для такой геометрии. Представлены преимущества геометрии «строго назад» по сравнению с другими геометриями в зависимости от интенсивности, спектральной ширины и возможности разделения вкладов от различных механизмов излучения в общий выход излучения.

\section{ДОСЛІДЖЕННЯ ПАРАМЕТРИЧНОГО РЕНТГЕНІВСЬКОГО ВИПРОМІНЮВАННЯ В ГЕОМЕТРІї «СТРОГО НАЗАД»}

\section{В.І. Алексєєв, А.Н. Єлисєєв, Е.Ф. Іррібарра, І.А. Кищин, А.С. Кубанкин, Р.М. Нажмудинов}

Аналізується параметричне рентгенівське випромінювання, зареєстроване в геометрії «строго назад». Обговорюються основні властивості випромінювання для такої геометрії. Представлено переваги геометрії «строго назад» у порівнянні з іншими геометріями в залежності від інтенсивності, спектральної ширини і можливості поділу внесків від різних механізмів випромінювання в загальний вихід випромінювання. 